\title{
The role of community development in improving awareness, diagnosis and management of childhood non-communicable diseases (NCDs) in Indonesia
}

\author{
Aman Pulungan ${ }^{1,2,3^{*}}$, I Wayan Bikin Suryawan ${ }^{3}$, Kate Armstrong ${ }^{4}$, Dwi Lestari Pramesti ${ }^{1}$ \\ From 8th APPES Biennial Scientific Meeting \\ Darwin, Australia. 29 October - 1 November 2014
}

\section{Background}

NCDs are now recognised as a major public health problem globally. In Indonesia, WHO estimates that $63 \%$ of all deaths are caused by NCDs. Lack of community awareness and health systems ill-equipped to deal with NCDs contribute to misdiagnosis, underdiagnosis, and increased preventable morbidity and mortality, particularly for children and adolescents.

\section{Objective}

To raise awareness and improve the diagnosis and management of childhood NCDs in Indonesia.

\section{Method}

Established NCD Family Communities: IKADAR (Type1 Diabetes) in 2003, YTI (Turner's Syndrome) in 2003, KAHAKI (Congenital Adrenal Hyperplasia) in 2008 and FOSTEO (Osteogenesis Imperfecta/OI) in 2013. Community development approach, with focus on education, research (collation of data from IPS registries at Cipto Mangunkusumo Hospital), advocacy and health systems strengthening.

\section{Results}

Establishment of clubs and registers increased known prevalence across Indonesia: a 4.5 fold increase in $\mathrm{CAH}$, from 65 patients (2008) to 293 (2014); 2 fold increase in OI, from 35 patients (2013) to 70 (2014); 5 fold increase in Diabetes, from 156 patients (2009) to 960 (2014). Access to medicines improved: donations of hydrocortisone (oral and injectable) and fludrocortisone co-ordinated by KAHAKI and CLAN, with efforts to register nationally; bisphosphonates included in national insurance scheme following launch of FOSTEO. Translation of educational resources and focused training for health professionals coincided with reduced presentations of children to hospital in adrenal crisis and diabetic ketoacidosis and reduced mortality from $\mathrm{CAH}$ and Diabetes. Media reports increased across all groups and information sharing amongst community members enhanced by WhatsApp.

\section{Conclusions}

The experiences of NCD Communities in Indonesia offer insights into practical steps that can be taken to redress the inequitable plight of young people living with NCDs in the Asia-Pacific region. A community development focus drives sustainable change,and helps increase awareness. Awareness makes a difference.

\section{Authors' details}

'University of Indonesia, Jakarta, Indonesia. ${ }^{2}$ Cipto Mangunkusumo Hospital, Jakarta, Indonesia. ${ }^{3}$ Indonesia Pediatric Society, Jakarta, Indonesia. ${ }^{4}$ Caring and Living as Neighbours (CLAN), Australia.

Published: 28 April 2015

doi:10.1186/1687-9856-2015-S1-P83

Cite this article as: Pulungan et al:: The role of community development in improving awareness, diagnosis and management of childhood noncommunicable diseases (NCDs) in Indonesia. International Journal of Pediatric Endocrinology 2015 2015(Suppl 1):P83.

University of Indonesia, Jakarta, Indonesia

Full list of author information is available at the end of the article 